\title{
In Memoriam of Prof. Bing Xia, MD, PhD
}

Guoying Zhou, MD; Jing Wu, MD; Qin Ouyang, MD; Harry Xia, MD; Jun Sun, PhD; Juei-Tang Cheng, MD; Servaas A. Morré, PhD; J. Bart A. Crusius, PhD; Weixi Xia, BSc and A. Salvador Peña, MD; on behalf of Bing Xia's friends

(Supplementary material)

Bing Xia was a Chinese gastroenterologist, a leader in the field of inflammatory bowel disease (IBD) in China. He died on December 31, 2014 at the age of 58 of pancreatic cancer in the very department he was leading in Zhongnan Hospital, Wuhan, P.R. China. He was born in Hubei province, China on December 26, 1956. He married to Zi Zheng ("Lily" for the friends abroad) in January 1986. Their son Weixi Xia was born in October 1986. Bing Xia was a gifted versatile talented person; he played the violin, guitar, erhu (a Chinese musical instrument) and was a successful photographer. He mastered Chinese calligraphy and traditional Chinese painting. He also played well at table tennis (Ping-Pong) and basketball. Prof. Bing Xia became Head of the Department of Gastroenterology, Head of Department of Internal Medicine, and Head of the Research Center for Digestive Diseases at Zhongnan Hospital affiliated to Wuhan University School of Medicine.

In October 1993, Bing Xia arrived in Amsterdam at the Laboratory of Immunogenetics of the VU University medical center to study the genetic predisposition of IBD with J. Bart A. Crusius PhD. Bing Xia wrote a thesis in 1998 on: "Immunological and immunogenetic studies in inflammatory bowel disease. Experimental and clinical aspects" at the "VU" University Amsterdam.

At the time he collaborated in studies on the epidemiology of IBD at the University of Maastricht with Professor S. Shivananda, epidemiologist and with Professor R. Stockbrugger and Dr. Maurice Russel, gastroenterologists. Bing Xia's thesis is important for the foundation it has provided, in a pioneer way, to initiate the research on IBD in Wuhan. After returning to China, Bing Xia was promoted to senior positions and has been active in all academic fields of IBD.

Dr. Guoying Zhou has written:-"I feel very proud to be Prof. Xia's student and I'm very grateful for his supervision and selfless help to me. He recommended me to do PhD study in Erasmus Medical Center in Rotterdam, the Netherlands in 2013 and gave me a lot of support; I will never forget his encouragement by saying "Try your best to achieve more". On 26th December 2014, I received his 58 -year old birthday photo with his students and colleagues from China, his skinny body shocked me but his "V" gesture-victory

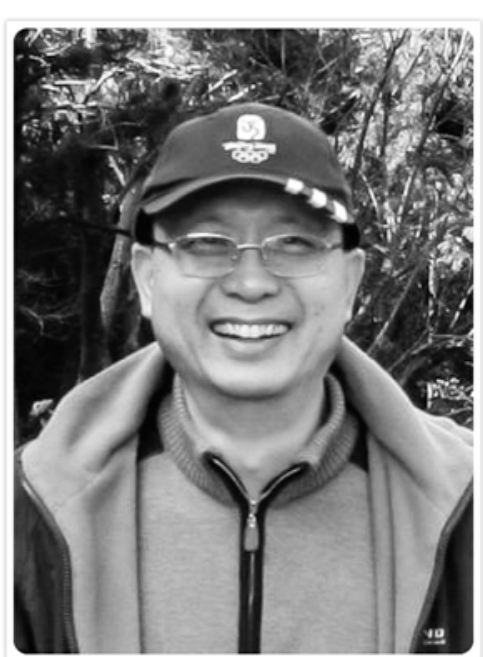

Bing Xia, MD, PhD 


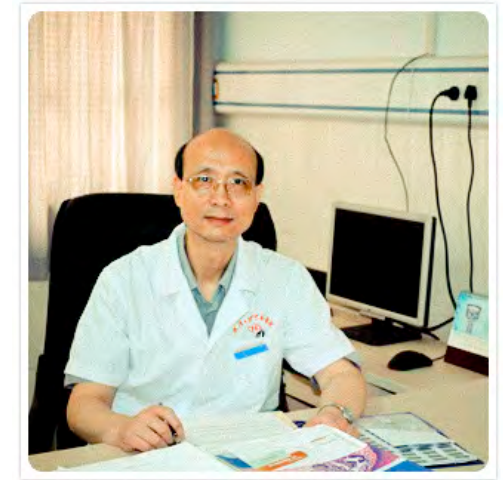

Bing Xia, MD, PhD sign even impressed me more! Yes that's how he is, dauntless and optimistic. His spirit will inspire me forever, in my career and my life".

As Professor Jing Wu from "Affiliated Hospital of Nanjing University of Traditional Chinese Medicine" writes, -"Bing Xia was a remarkable clinical scientist. He had new findings every year, especially concerning the knowledge of IBD in China. His team found that NOD2 3020insC frameshift mutation is not associated with IBD in Chinese patients of Han nationality. In the last few weeks, although very weak and as a consequence he had to stay in his hospital bed for nutritional support, he remained dedicated to his patients, students, $\mathrm{PhD}$ fellows as well as colleagues. He was a dedicated physician. When patients needed his help, he was always ready to advice. This can be reflected by the fact that hundreds of patients spontaneously attended his memorial. Bing Xia was a beloved teacher and supervisor of more than fifty Master and $\mathrm{PhD}$ students. One week before he died he still stimulated and guided his $\mathrm{PhD}$ students and corrected their manuscripts for publication". Professor Jing Wu further writes that Professor Bing Xia had a perfect combination of dedication, tenacity, and humbleness. She believes that this is the reason why so many people respect and admire him in China and abroad.

Prof. Qin Ouyang from Sichuan University, at Chengdu, China writes: "Bing Xia was a true friend and helped a lot of people to fulfill their dreams and give them the best support both at home and abroad where they were pursuing specialization. He was a leader as vice director of the group for IBD in China and promoted the communication between China and colleagues around the world. He became an outstanding scholar and a trusted friend. He left an outstanding contribution to the Chinese IBD academic research groups. His spiritual wealth lives in our mind".

In Wuhan, Bing Xia engaged in genetic research that had been started in Amsterdam. He then became part of a number of research groups of IBD and celiac disease in China and abroad. More recently he became interested and contributed to the new field of intestinal flora in the pathogenesis of IBD.

Harry Xia, also originally from Wuhan, knew Bing Xia when they were outside China through academic communications and research cooperation. He has trained several doctors who came from Bing Xia's department. In a three month visit to The University of Hong Kong as a visiting professor, Harry Xia writes: Bing Xia demonstrated his talent in and desire for medical research. He also demonstrated his strong leadership, organization ability and time management skills as a head of his department in Wuhan. I knew he suffered from kidney cancer in 1995, and fully recovered after operation. However, as Weixi Xia has reminded me, in July 2010 he was diagnosed with pancreatic cancer. After a Whipple operation in Zhongnan Hospital in Wuhan, Bing Xia did very well till May of 2013 when metastasis were discovered in the thoracic 
vertebra and treated. On August 14, 2014 he looked much better than just one year ago. He had very high spirit with optimistic attitude; he was organizing the Ninth IBD Workshop, 2014, Wuhan. Although the workshop held on October 11-12, was a great success, unfortunately, Bing was not able to attend personally. I met Bing in his ward on the afternoon, October 12, and wished I could meet him again next year. China lost a great scientist! Zhongnan Hospital lost an outstanding doctor! I lost a close brother! Bing will be in my heart forever!"

Prof. Servaas Morré commented: -"His excellent mentorship and devotion to his students and $\mathrm{PhD}$ fellows was also seen clearly when he and Dr. Guifang Yang invited me as speaker in November 2006 to the 50th anniversary of the Wuhan University Zhongnan Hospital. Before the meeting he very kindly invited a small group for a trip along the Yangtze River and the Three Gorges Dam. We had a meeting with 25 of his students who gave presentations followed by broad and vivid discussions. The excellent training they got from him was so obvious, he sparkled the minds of the new generation". As Prof. Qin Ouyang further writes Bing Xia actively participated in Chinese IBD study group activities, became the earliest key member of the Chinese IBD organization and the banner of genetics research and was then selected as deputy head of this organization.

In recent years, with the national research project, Bing Xia collaborated with several IBD centers in China, to study IBD genetic characteristics, and obtained creative accomplishments. He was also actively involved in a number of domestic and overseas cooperative research projects and a series of academic activities. He was reviewer of many international academic journals, such as Gastroenterology, Medicine, American Journal of Gastroenterology, Journal of Gastroenterology and Hepatology and Inflammatory Bowel Disease. Many articles have been published in the relevant journals with great impact on the sphere of academy and greatly promoted the internationalization of China's IBD. The textbook "Inflammatory Bowel Disease" he edited has been revised twice and became more and more instructive in P.R. China. Bing Xia has also become a world well-known IBD expert due to his research and academic achievements.

His academic spirit and personality left us a good memory. In the struggle with cancer in recent years, Bing Xia fought tenaciously with serious pain, conducted exemplariness and nobility of his character and continued the pursuit of scientific research, which is admiration of us all. The body of a man could not get back, but the soul of the scholar will persist in our memories. We mourn the death of scholar and friend, we should learn from him in his international vision and persistent pursuit; in truth-seeking and coordination of academic exchange; in tenacious fighting spirit with cancer; and in making friends sincerely, friendly and courteous attitude. Let us uphold the man's perspective to continue pursuit ahead, and take

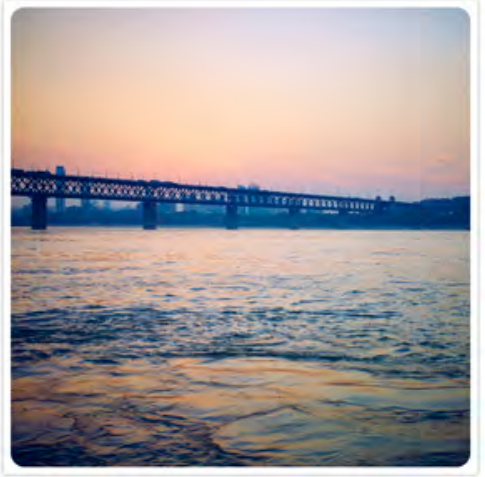

The Yangtse River,WuHan 


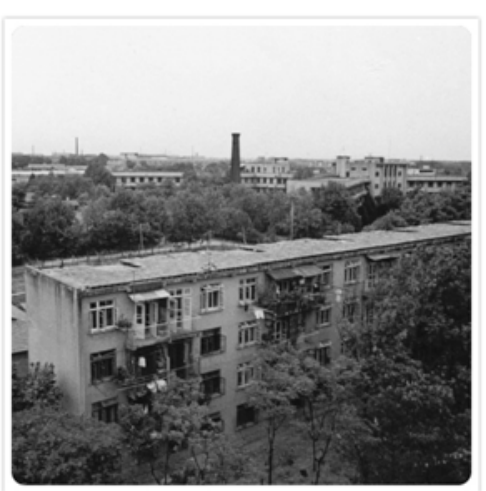

Employee's Dormitory of Zhongnan Hospital of Wuhan University In 1970's more effort in research on IBD, for the benefit of our patients".

Together with Ms. Dr. Siew C Ng from Hong Kong Bing Xia performed the first population based IBD study in Wuhan. Dr. Siew $\mathrm{C} \mathrm{Ng}$ and Prof. Michael Kamm visited him in Wuhan and were touched by his hospitality and passion for research and dedication to his patients. They published the first study on IBD incidence in China two years ago and since then continued further collaboration in many aspects of IBD. Prof. Bing Xia's fellow, Dr. Jin Li joined the unit of Dr. Siew C Ng in Hong Kong for 6 months. Dr. Jin Li and Professor Bing Xia edited a book on IBD which was recently completed. Dr. Siew C Ng writes that Bing Xia was a lovable and honorable man and wishes strongly that he may rest in peace. Professor Juei-Tang Cheng (Chair-professor in Institute of Medical Sciences, Chang Jung from the Christian University, Tainan, Taiwan) writes: "You are fixed in my heart and I will miss the date we have had in co-lab works. Be wonderful with God, my good friend gentlemen Bing Xia".

Throughout his life, Dr. Xia touched the lives of numerous other scientists through collaboration, as a mentor and as a friend. Jun Sun, PhD., AGAF from Rush University, Chicago, USA, started cooperation with Dr. Bing Xia in 2008. Dr. Xia had great interest in understanding the role of the microbiome in IBD, a research direction different from his original genetic studies in human IBD. In the past years, he also worked very hard on this subject and contributed his new findings to the field.

Dr. Simon Travis from Oxford who visited Bing Xia few months before his death writes that Bing Xia was an enthusiastic person and mentor who lived through difficult times and created something special in Wuhan. He further added that we in the West can have no concept about what he and his parents lived through, yet he survived to create. That's a really remarkable person.

Dr. Gary L. Norman, Director of Research and Development of Inova Diagnostics writes that he will always remember his last visit to Bing Xia only a few months before his death. Although he was in his hospital bed, he greeted him with a big smile and such warmth and friendship that the hospital bed was quickly forgotten. He adds: "We discussed China, food, and planned studies which would extend years into the future. These studies will continue in his memory. "I will miss him as a colleague and a friend". Professor C. Janneke van der Woude an IBD expert in Rotterdam, the Netherlands can testify the affability and helpfulness of Bing Xia when she and other Dutch gastroenterologists visited Zhongnan hospital in Wuhan. Professor Jean-Louis Guéant, Head of the Department of Molecular Medicine and Personalized Therapeutics at the National Center of Inborn Errors of Metabolism in Nancy, France was very impressed by Bing Xia's courage, knowing that he has been helping his PhD students until the end. -“I will keep forever the very nice time that we had together, including for the $\mathrm{PhD}$ training of Dr. Min Chen, in Wuhan and Nancy". Prof. Jiang 
Chang from the Center for Translational Cancer Research from Houston, Texas wrote that Bing is an example of an outstanding scientist, educator and doctor with highest integrity. He was a kind of friend when you know him, you want to cherish forever.

Dr. Yong Qin who is now at the Biotechnology Center Shanxi Academy of Agricultural Sciences, Long Cheng, Taiyuan, Shanxi, China but in 2007 in Leiden, the Netherlands met Bing Xia, Jing $\mathrm{Wu}$ and Dr. Guifang Yang at the Laboratory of Immunogenetics during his PhD studies. He remembers Dr. Xia for his valuable advice on his research projects, his great personality, great sense of humor and he always created a friendly and joyful communication atmosphere. He added that Dr. Xia was an excellent mentor and a true friend.

David T. Rubin, MD from Chicago writes that Bing Xia's legacy of scholarship and collegiality will be preserved in the work we all continue to do together. Dr. Ad A. van Bodegraven, an IBD expert from Amsterdam wrote "Bing was a good colleague from China representing the best of an open scientific mind and an excellent friend whenever and wherever we met. May his family find strength in and support from our high esteem of this fine fellow". Jerry Rotter, MD, from the Los Angeles Biomedical Research Institute LA BioMed, simply but truthfully wrote "Bing Xia was a scholar and a gentleman".

We like to finish this obituary with the deepest feeling that only a son can write at the deathbed of a loved father. Bing Xia's son, Weixi Xia BSc writes: "The most amazing thing is that my father insisted to work to the very last time of his life, he deployed doctors and nurses in his department, arranged the schedule and plan for his subordinates, guided his students, discussed important issues with leaders in the hospital. He did everything just in his ward. He died on the 31 Dec 2014. On the 2 Jan 2015, according to the Chinese tradition, we had his funeral, about 300 people attended his funeral".

Dr. Jun Sun wrote that "I am very impressed that in 2014, Dr. Xia published 3 papers to report the IBD-associated microbiome in leading peer-reviewed journals, including Gut, Medicine, and Journal of Clinical Microbiology". Dr. Xia also worked on the new version of IBD text book for the Chinese medical students. He was so excited to introduce the new concept about gut microbiota in IBD to students. Dr. Xia leaves a solid legacy of scientific discovery and achievement. He will be missed by family, his friends, his students, and the many physicians and scientist around the world for whom he was an inspiring colleague".

本文来源：Medicine Correspondence Blog Monday, September 21, 2015 